\title{
A CONTEMPORARY METHOD OF EMPLOYEES ASSESSMENT
}

\author{
Wiktor Adamus \\ Jagiellonian University Kraków, Poland \\ E-mail: wiktor.adamus@uj.edu.pl
}

\begin{abstract}
Evaluation of human capital (by nature immeasurable) has become the greatest challenge in terms of the personal function. Although many evaluation methods have developed, none of them accurately measures the value of personality, behavioral, qualification or effectiveness criteria. The aim of this paper is to draw up a new method measuring employees qualitative traits in a simple, transparent and universal way. Basis the employees assessment method on cognitive psychology and applied mathematics opens up new possibilities in the field of human resource management in organizations.
\end{abstract}

Keywords: human, resource, management, employees, assessment.

\section{Introduction}

Human resource management is an essential feature of every organization. Alongside capital, financial, technological and information capitals, human resources constitutes the most important capital in every organization (human capital). It is the people who lead organizations to success, but also act as a go-between in their fall. Modern literature presents various approaches to the issue of human resources management. The authors of works in this field agree an organization's efficiency above all depends on its employees. The competence of people, the ir knowledge, experience, skills, cooperation and responsibility all become a resource of strategic importance allowing organizations to gain competitive advantages. Among the four functions of human resource management (Michigan model): selection, appraisal, rewards and development, reference books (especially those written in the final decade of the twentieth century and in the beginning of the twenty first century) pay most attention to the function of appraisal. Evaluation of human capital (by nature immeasurable) has become the greatest challenge in terms of the personal function. Although many evaluation methods have developed: Descriptive assessment, The point scale of evaluations, Weighted scales, Ranking, Normal distribution technique, Critical events technique, Testing method of an evaluation, , Assessment Centre (AC), Development Centre (DC), System of comparison in pairs, Multi-source feedback ( MSF $360^{\circ}$ ), Personal portfolio (portfolio method) based on the BCG matrix (Boston Consulting Group), Management by objective (MBO), none of them accurately measures the value of personality, behavioral, qualification or effectiveness criteria. The aim of this paper is to draw up a new method measuring employees qualitative traits in a simple, transparent and universal way. This method is an expansion of previous evaluation methods, collected practical experiences and utilization of contemporary knowledge in the areas of cognitive psychology, behavior in organizations and applied mathematics, including multi-criteria methods of supporting decisions. This is another article (Adamus 2009 a, b) about the measurement of the value of human capital. They open up new possibilities in the study of human resources management.

\section{The essence of employees assess ment}

The assessment of traits, competence or results of individuals or teams work plays a vital role in every organization. People assess themselves and others, but they are also assessed by team members in which they work and their superiors. These assessments are made on all management stages. 
Reference books provide dozens of definitions of periodic job evaluation ( Czubaszkiewicz 2005). For our purposes job evaluation shall mean ( Król, Ludwiczyński 2006): a value judgment in the process of management which comes into existence as a result of the comparison of traits, qualifications, behaviors or effects of a specific employee's work with reference to other employees or a standard. Having to choose from several methods of evaluation superiors constantly face the problem of assessment. The choice of an appropriate method is extremely difficult for every company director as each one sets huge requirements. He must get to know its basics and intentions and gain competence necessary for its realization in practice.

Evaluation methods fulfill many, often contradictory functions. While some of them deepen the rigor of work, others support the development of an employee and his or her motivation. The main goals of employees assessment are ( Steinmann, Schreyögg 1998): determining the basics for the diversification of wages and salaries exceeding job evaluation, justification of personal decisions, an evaluation of the efficiency of tools of personal politics, gaining information for training and improvement of qualification, increasing motivation and supporting the individual development of members of an organization Informing employees about the results of the evaluation and the possibility of professional development in their workplace. A simultaneous realization of these goals together with the application of the above mentioned evaluate employees methods often leads to role conflict which results in an ambivalent attitude towards job evaluation systems. Hence, there exists a need of drawing up a new method which may equally well evaluate employees and their superiors, and which may resolve conflicts between the evaluated employee and his or her development. The number of compared elements " $n$ " should be included between 5-9. This range is based on the socalled magical number seven, that is $7+/-2$ ( Miller 1956). With a larger number of compared criteria there exists a greater risk of expressing erroneous opinions and conclusions. It results from the fact that the human mind cannot grasp a larger number of variables and faultlessly compare them in a relatively short period of time. These facts were repeatedly confirmed in psychological literature (Blumenthal 1977, Tversky 1971, Larichev 1984, Larichev, Moshkovich, Rebrik 1998). People prefer verbal communication than qualitative communication. Words are perceived as more flexible and less precise and therefore seem to fit better into the description of vague opinions. I. Erev and B. Cohen have found that forcing people to provide numeric expressions, statements concerning unclear situations when they can only differentiate between a few probability levels may lead to confusing estimates (Erev, Cohen 1990). Research has shown that qualitative assessment and comparison of different objects is more difficult for humans than conducting the same operations with the use of qualitative tools for expressing preferences ( Moshkovich at all 2005). Hence, this employees assessment method shall use scales based on verbal descriptions, which after their quantification (scaling) will provide a quantitative aspect for criteria in employees assessment models. The number of criteria and sub-criteria will not exceed 7 in the proposed method.

\section{Steps in the measurement method of qualitative features of employees}

In employees assessment the following stages are proposed:

1. Introducing the problem - developing a new method of measuring quality features of jobs in a simple, transparent, universal way,

2. Identifying the main goal - a relative assessment of job posts in an organization,

3. Recognition of internal and external factors determining the value of job posts,

4. Establishing a multi-level structure of the problem in the form of a hierarchical tree, main goal, main criteria and sub-criteria (level of intensity) of each criteria (Fig. 1), 
5. Determining the dominance (preferences) of synthetic criteria by comparing in pairs (one with another) their importance (verbal opinions) with reference to job value based on the fundamental preference scale of T. Saaty (Saaty 2006),

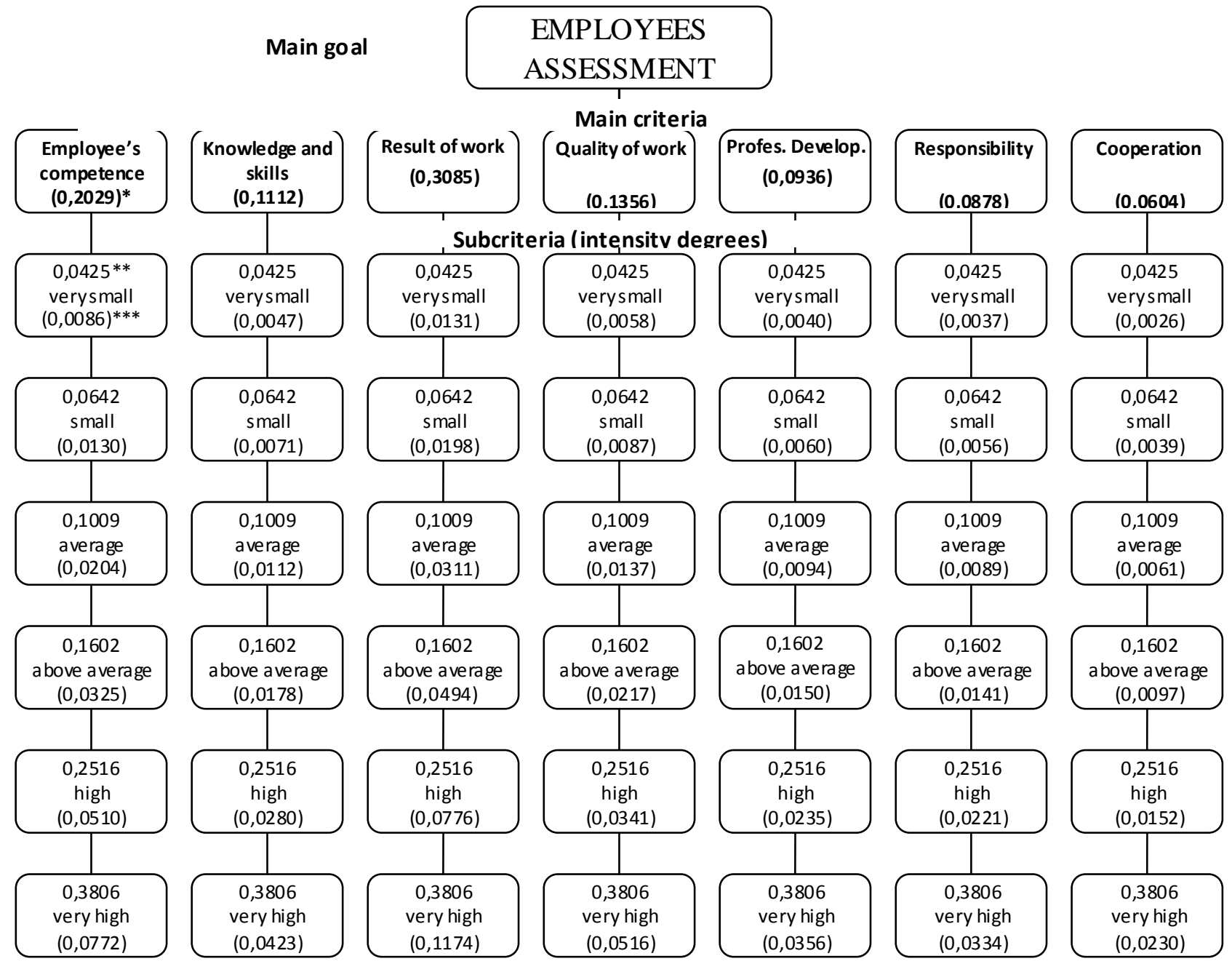

Figure 1. The hierarchical structure of employees assessment

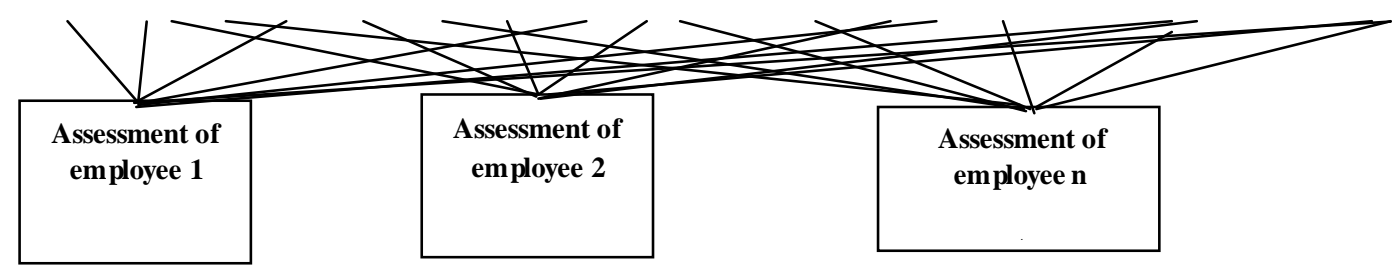

Source: personal study

*The numerical priority determining the weight of the evaluation criterion,

**The numerical priority of a verbal evaluation written at the top indicates local weight,

***A priority written at the bottom in brackets indicates global weight, the sum of weights equals the priority of the main criterion. 
These comparisons are made by experts, researchers - specialists in the field of human resource management, practitioners - human resource directors, company managers,

6. Quantification of verbal opinions on importance of comparison of synthetic criteria

7. Quantification of verbal opinions on importance of comparison of sub-criteria (intensity degrees).

8. Determining "local" priorities (weights) in the [>0,<1] bracket for each $P_{K_{i}}$ criterion and subcriterion $P_{S_{i j}}$ through the normalization of own vectors from the comparison matrix.

9. Determining the global priority $P_{g_{i j}}$ for each analytical criterion on the basis of the following formula:

$$
P_{g_{i j}}=P_{K_{i}} \times P_{S_{i j}}
$$

10. Description and analysis of individual employees including evaluation criteria expressed by a verbal, adjectival degree of intensity of each criteria. The task of the person describing the post is a verbal objective assessment in a six-point adjectival scale of the intensity of the criteria ascribed to a given employee.

11. Determining the number of points for each employee $W_{s_{i}}$ by means of the following formula:

$$
W_{s_{i}}=\sum_{j=1}^{n}\left(P_{g_{i j}} \times 10000\right)
$$

\section{Hie rarchy of employees assessment issues}

The idea of the presented method is simple and universal. Hence, developing a system of job evaluation 7 main criterions have been adopted: an employee's competences (qualifications), knowledge and skills, work effects in a given period, quality of work in an assessed period, professional development, responsibility and coope ration (Fig. 1).

\section{Quantification of ve rbal opinions}

Each criteria was assigned six sub-criteria - adjectival, verbal degrees of intensity (Fig. 1). Every person takes dozens of decisions each day considering different criteria as to alternatives which fulfill a set of desirable effects.

The idea of this method is the exponential increase of numerical values of analytical evaluations (intensity) in comparison with verbal evaluations. The aim of such action is causing a strong, healthy competition between employees in a company working in different job posts. A higher post in the organizational structure of a company related to the analytical criteria is "rewarded" with a higher exponential priority (weights) and numerical intensity of the criterion. However, it is not directly proportional to verbal evaluation.

\section{An integrated employees assessment system}

The calculations of numerical priorities for criteria and CR conformity rates were aided by the Expert Choice computer program. The numerical priorities (weights) of all criteria and sub-criteria are presented in figure 1. After assessing the numerical values for main and sub-criteria in job evaluation a certain system allowing to evaluate each employee with respect to the sum of points obtained in the evaluation (table 1) was proposed. An appropriate number of points was assigned verbal evaluations commonly used in job evaluation in organizations from poor to excellent. The sum of points for different job evaluations and assigning verbal evaluations to them was determined in the following order:

1. The total possible sum of points for each intensity degree that an evaluated employee may receive for all main criteria was calculated from figure 1: 
a)very small - 425pkt, b) small - 642pkt, c) average - 1009pkt,

d) above average - $1602 \mathrm{pkt}$, e) high - 2516pkt, f) very high - 3806pkt

2. The mean average of points for neighboring intensity degrees was calculated:

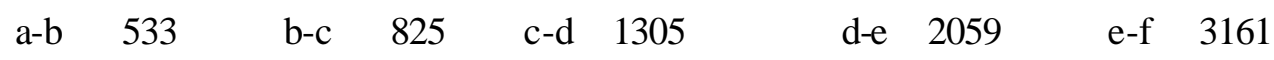

3. The calculated amounts were adopted as limit ones for the verbal description of job evaluation

4. The adopted amounts of points were assigned verbal evaluations

5. The meaning of verbal evaluations was described

Table 1. Point and verbal employees assessment

\begin{tabular}{|c|c|c|c|c|c|}
\hline \multicolumn{6}{|c|}{ PO I N T GRA D E (sum of points) } \\
\hline$>3161$ & $2060-3161$ & $1306-2059$ & $826-1305$ & $533-825$ & $<533$ \\
\hline \multicolumn{6}{|c|}{ VERBAL EVALUATION } \\
\hline Excellent & Great & Satisfactory & Good & Unsatisfactory & Poor \\
\hline $\begin{array}{l}\text { Considerably } \\
\text { exceeds standards } \\
\text { and values } \\
\text { determined in an } \\
\text { organization and } \\
\text { significantly } \\
\text { exceeds } \\
\text { expectations }\end{array}$ & $\begin{array}{l}\text { Exceeds } \\
\text { standards } \\
\text { and } \\
\text { expectations }\end{array}$ & $\begin{array}{l}\text { Slightly above } \\
\text { expectations }\end{array}$ & $\begin{array}{l}\text { According to } \\
\text { expectations }\end{array}$ & $\begin{array}{l}\text { Slightly be low } \\
\text { expectations }\end{array}$ & $\begin{array}{l}\text { Far below } \\
\text { expectations }\end{array}$ \\
\hline
\end{tabular}

\section{Examples of job e valuation:}

\section{Employee $1 \quad$ Employee $2 \quad$ Employee 3}
a. Competence
average
high
small
b. Knowledge and skills
high
high
above average
c. Work results
average
above average
average
d. Quality of work
above average above average
above average
e. Professional deve lopment
small
average
high
f. Responsibility
high
very high
average
g. Cooperation
small
high
very small
1332
2081
1186
satisfactory
good
proper

Total sum of points

Verbal evaluation 


\section{Conclusion}

Employees assessment is a complex tool used in the process of human resource management. Such evaluation covers qualitative and quantitative aspects of organizational functioning of individuals and answers the question to what extent an employee fits into the arranged standards and values adopted by an organization. This paper was aimed at establishing a method fulfilling the above statement. A detailed analys is of the employees assessment process enabled us to observe the immense complexity of the issue and helped to thoroughly assess the diverse connections and relations, as well as ascribe each criterion a weight in the form of a numerical priority. It was possible thanks to the trailblazing use of one of the multi-criteria problem solution method AHP of Prof. T. Saaty.

The established methods is unique as comparing to other techniques in the following respects:

1. The simplicity rule - unequivocal, not raising reservations a signability of priorities for the seven main evaluation criteria as a result of comparisons made in pairs. In the proposed method we compare verbally in pairs the values of criteria according to which employees are evaluated, not individuals or job posts.

2. The universality of the proposed method is based on the fact that employees assessment may be only performed by a superior or by co-workers, exterior clients, subordinates and self-evaluation. The evaluators evaluate seven criteria in a six-point verbal scale, from very small to very high. The final grade is determined by adding up the values of global weights resulting from assigning for each criterion a suitable verbal evaluation to the evaluated employee,

3. In contrast to other point and analytical methods, here the relations between studied factors are nonlinear - similarly to the real world,

4.The final weight (priority, intensity) for a given analytical factor is a multiplicative quantity, translating the value from the main criteria to point grades of the evaluated employee (intensity). This way a certain continuity (progress) in job evaluation was provided,

5. The possibility of applying the presented method for evaluation of all employees in an organization,

6. Basing the employees assessment method on cognitive psychology and applied mathematics opens up new possibilities in the field of human resource management in organizations.

\section{REFERENCES}

Adamus ,W.(a) (2009). A new method of job evaluation. http//www.isahp.org/2009. Proceedings/Final_Papers/ 106_Adamus_REV_FIN.pdf, 20.09.2009.

Adamus, W.(b) (2009). An integrated system of job evaluation [in:] Management organizations in a competitive economy, (ed. SL Lachiewicz, A. Zakrzewska - Bielawska) Monographs Technical University of Lodz.

Lodz (polish)Zintegrowany system wartościowania stanowisk pracy [w:] Zarządzanie organizacjami w warunkach konkurencyjnej gospodarki, (red. S. L. Lachiewicz, A. Zakrzewska - Bielawska) Monografie Politechniki Łódzkiej, Łódź, 260- 273.

Blumenthal ,A. L. (1977). The Process of Cognition, Prentice-Hall, Inc., Englewood Cliffs, New Jersey. 
Czubaszkiewicz H.(2005). Periodic evaluation of employees. Configuration and system design. Publisher University of Gdansk, Gdańsk (polish) Okresowe ocenianie pracowników . Konfiguracja i projektowanie systemu. Wydawnictwo Uniwersytetu Gdańskiego, Gdańsk, 110.

Erev, I., Cohen, B.(1990). Verbal versus numerical probabilities: Efficiency, biased, and the preference paradox. Organizational Behavior and Human Decision Processes, 5:1-18.

Król, H., Ludwiczyński, A. (2006). Human Resource Management, Scientific Publishers, Warsaw (polish).

Zarządzanie Zasobami Ludzkimi, Wydawnictwo Naukowe PWN, Warszawa, 275.

Larichev, O. I. (1984). Psychological validation of decision methods. Journal of Applied Systems Analysis, No 11, 37-46.

Larichev, O., I., Moshkovich, H. M., Rebrik, S.B. (1998). Systematic research into human behavior in multiattribute object classification problems. Acta Psychologica, 68: 171-182.

Miller, H. A. (1956). The Magical Number Seven, Plus or Minus Two: Some Limits on Our Capacity for Processing Information, Vol. 63, No. 2, 81-97.

Moshkovich, H.M., Mechitov, A. L., Olson D.L. (2005). Verbal Decision Analysis [in:] Multiple Criteria Decision Analysis: State of the Art Surveys, edited by J. Figueria, S. Greco, M. Ehrgott, Springer, 609-637.

Saaty, T. L. (2006). Fundamentals of Decision Making and Priority Theory with the Analytic Hierarchy Process, Vol. VI of the AHP Series, Pittsburgh: RSW Publications.

Steinmann, H., Schreyögg, G. (1998). Management, company management basics, concepts, features examples. Publishing House Wroclaw University of Technology, (polish) Zarządzanie, Podstawy kierowania przedsiębiostwem, Wrocław, 494- 495 Tversky, A. (1971). Elimination by aspect: A probabilistic theory of choice, Michigan Mathematical Psychology Program MMP 71 - 12. The University of Michigan. Ann. Arbor., Michigan. 